\title{
Inhibition of estradiol synthesis impairs fear extinction in male rats
}

\author{
Bronwyn M. Graham ${ }^{1,2}$ and Mohammed R. Milad ${ }^{1,3}$ \\ ${ }^{1}$ Massachusetts General Hospital and Harvard Medical School, Charlestown, Massachusetts 02129, USA
}

\begin{abstract}
Emerging research has demonstrated that the sex hormone estradiol regulates fear extinction in female rodents and women. Estradiol may also regulate fear extinction in males, given its role in synaptic plasticity in both sexes. Here we report that inhibition of estradiol synthesis during extinction training, via the aromatase inhibitor fadrozole, significantly impairs extinction recall in male rats. This deficit in extinction recall is not due to state-dependent memory formation and is completely abolished by coadministration of estradiol. Our data suggest that estradiol may be just as important in the regulation of fear extinction in males as it is in females.
\end{abstract}

Fear extinction is a laboratory model of exposure therapy for anxiety disorders (Graham and Milad 2011; Milad and Quirk 2012; Parsons and Ressler 2013). During extinction training a feared conditioned stimulus (CS) is repeatedly presented in the absence of the aversive unconditioned stimulus (US), until fear responses decline. Long-term retention of extinction is tested the following day by presenting the extinguished CS and measuring fear responses. Although the vast majority of research on fear extinction has been conducted using male rodents, more recent research has focused on fear extinction in females. The key finding that has emerged is that fear extinction is subject to considerable control by sex hormones, particularly estradiol (Lebron-Milad and Milad 2012). For example, fluctuations in estradiol across the menstrual cycle are correlated with the success of extinction; women and female rats that undergo extinction learning during the low estradiol phase exhibit impaired extinction recall the following day, relative to those undergoing extinction learning during the high estradiol phase (Chang et al. 2009; Milad et al. 2009, 2010; Zeidan et al. 2011; Glover et al. 2012; Graham and Milad 2013; Rey et al. 2013). A single dose of estradiol prior to extinction training abolishes these extinction deficits in healthy women (Graham and Milad 2013). Furthermore, in female rodents, estrogen agonists enhance, whereas estrogen antagonists impair, extinction consolidation (Chang et al. 2009; Milad et al. 2009). Finally, hormonal contraceptives, which inhibit estradiol synthesis, impair extinction in both rats and women (Graham and Milad 2013). Hormone-associated disruptions in extinction have been suggested as a potential mechanism contributing to women's increased vulnerability to anxiety disorders (Lebron-Milad and Milad 2012; Graham and Milad 2013). Indeed, low estradiol levels have been associated with diminished extinction learning and increased symptom severity in women with posttraumatic stress disorder (Glover et al. 2012).

Is the influence of estradiol on fear extinction unique to females, or could estradiol also regulate fear extinction in males? Studies that have demonstrated that, in both rats and humans, females exhibit similar extinction recall to males when they are extinguished during the high estradiol phase of the menstrual cycle, and exhibit impaired extinction recall relative to males when they

\footnotetext{
2Present address: School of Psychology, University of New South Wales, Sydney NSW 2052, Australia

are extinguished during the low estradiol phase (Milad et al. 2009, 2010). These seemingly paradoxical results may be accounted for by research suggesting that estradiol is an important regulator of synaptic plasticity in both females and males. Many effects of testosterone are mediated by estradiol, which is synthesized via the enzyme aromatase from circulating testosterone, as well as from testosterone produced de novo by neurons in the hippocampus (Gillies and McArthur 2010). Aromatase was originally thought to be most important in sexual differentiation and reproductive behavior (Wright et al. 2010). More recently it has been determined that aromatase and the associated synthesis of estradiol are also involved in affect modulation, adulthood synaptogenesis, and learning and memory (Garcia-Segura 2008). It is therefore possible that estradiol may be just as important in the regulation of fear extinction in males as it is in females. Such a hypothesis would account for why sex differences in fear extinction emerge when females have reduced levels of estradiol.

If it is the case that estradiol is necessary to fear extinction in males, then blocking the conversion of testosterone to estradiol by inhibiting aromatase should impair fear extinction. We tested this hypothesis by examining the effects of the aromatase inhibitor, fadrozole (FAD), on the acquisition and consolidation of fear extinction in male rats. In all experiments, on Day 1 rats underwent habituation (five CS presentations alone, where the CS was a $30-\mathrm{sec}, 4-\mathrm{kHz}$ tone with $80-\mathrm{dB}$ intensity) followed by conditioning (five CS presentations coterminating with a 0.5-sec, 0.6-mA foot shock US). On Day 2, $24 \mathrm{~h}$ after fear conditioning, rats underwent extinction training consisting of 30 nonreinforced CS presentations (intertrial interval $60 \mathrm{sec}$ ). On Day 3, $24 \mathrm{~h}$ after extinction training, all rats were tested for extinction recall, consisting of three nonreinforced CS presentations. All procedures took place within the same context. Rats were scored for the percentage of time spent freezing during the CS presentations throughout all phases as a measure of fear. The freezing responses during each 30-sec trial are presented for conditioning and extinction recall. For extinction training, the freezing responses for every five extinction trials was averaged, and presented as six blocks of extinction trials.

C 2014 Graham and Milad This article is distributed exclusively by Cold Spring Harbor Laboratory Press for the first 12 months after the full-issue publication date (see http://learnmem.cshlp.org/site/misc/terms.xhtml). After 12 months, it is available under a Creative Commons License (AttributionNonCommercial 4.0 International), as described at http://creativecommons. org/licenses/by-nc/4.0/. 
Fear extinction in male rats depends on estradiol

Table 1. Pre-CS freezing levels prior to the first CS presentation during fear conditioning, extinction training, and extinction recall in Experiments 1-3

\begin{tabular}{|c|c|c|c|c|c|}
\hline \multirow{2}{*}{$\frac{\text { Experiment }}{\text { Experiment } 1}$} & \multicolumn{4}{|c|}{ Group } & \multirow[t]{2}{*}{ Analysis } \\
\hline & Vehicle & FAD-PRE & FAD-POST & FAD-4h & \\
\hline Preconditioning & $0(0)$ & $0(0)$ & $0(0)$ & $0(0)$ & n.s. \\
\hline Preextinction training & $9.17(5.63)$ & $13.33(6.94)$ & $9.17(3.63)$ & $1.5(1.07)$ & $F_{(3,45)}=0.88, P=0.46$ \\
\hline Preextinction recall & $4(3.02)$ & $2.67(1.1)$ & $6.75(4.15)$ & $0.5(0.5)$ & $F_{(3,45)}=0.87, P=0.46$ \\
\hline Experiment 2 & Veh-Veh & FAD-Veh & FAD-FAD & Veh-FAD & \\
\hline Preconditioning & $0(0)$ & $1.43(1.1)$ & $0.38(0.38)$ & $0.71(0.71)$ & $F_{(3,55)}=0.81, P=0.49$ \\
\hline Preextinction training & $2(1.18)$ & $6.79(4)$ & $8.1(5.53)$ & $2.86(1.55)$ & $F_{(3,55)}=0.76, P=0.52$ \\
\hline Preextinction recall & $0(0)$ & $0.71(0.71)$ & $3.69(3.44)$ & $0.43(0.29)$ & $F_{(3,55)}=1, P=0.4$ \\
\hline Experiment 3 & Veh-Veh & FAD-Veh & FAD $-17 \beta$ Est & & \\
\hline Preconditioning & $1.25(1.25)$ & $0(0)$ & $0.63(0.63)$ & & $F_{(2,23)}=0.6, P=0.56$ \\
\hline Preextinction training & $15.63(6.01)$ & $12.5(5.82)$ & $20.63(6.44)$ & & $F_{(2,23)}=0.45, P=0.64$ \\
\hline Preextinction recall & $3.88(2)$ & $0.38(0.38)$ & $1(1)$ & & $F_{(2,23)}=0.2, P=0.16$ \\
\hline
\end{tabular}

(n.s.) Not significant

Pre-CS freezing was measured in the 2-min acclimation period prior to CS onset throughout each experimental phase. In all experiments, pre-CS freezing was negligible, demonstrating that freezing during the CS was a reflection of the association between the CS and foot shock. Furthermore, no group differences in Pre-CS freezing were observed in any experiment (see Table 1).

In Experiment 1, rats were s.c. administered $1 \mathrm{mg} / \mathrm{kg}$ of body weight FAD 30 min prior to extinction training (group FAD-PRE), immediately after extinction training (group FAD-POST), or $4 \mathrm{~h}$ after extinction training (group FAD-4 h). Doses in this range have previously been shown to have rapid effects on behavior (Alejandre-Gomez et al. 2007; Taziaux et al. 2007). A fourth group of rats received an equivalent volume of vehicle at one of these time points, and were subsequently collapsed into one group (group Vehicle). No between-group differences in freezing levels were found throughout conditioning, as to be expected given that all drug manipulations occurred at the time of extinction training (Fig. 1). A repeated measures Analysis of Variance (ANOVA) revealed a significant effect of conditioning trial $\left(F_{(4,168)}=33.607, P<0.0001\right)$, and no effect of group nor a significant trial-by-group interaction $\left(P^{\prime} \mathrm{s}>0.416\right)$, indicating that all groups increased freezing throughout conditioning comparably. In addition, all groups exhibited comparable and declining levels of freezing throughout extinction training, as confirmed by a repeated measures ANOVA (significant effect of extinction block, $F_{(5,210)}=66.751, P<0.0001$, and no significant effect of group or a significant block-by-group interaction $\left(P^{\prime} \mathrm{s}>0.499\right)$. At extinction recall, a repeated-measures ANOVA revealed a significant effect of group $\left(F_{(1,42)}=17.194, P<0.001\right)$. Tukey's Honestly Significant Differences (HSD) test revealed that Vehicle exhibited significantly less freezing than FAD-PRE and FAD-POST $(P<$ $0.0001)$; the latter two groups both exhibited high and comparable levels of freezing $(P=0.71)$. FAD -4 h exhibited low levels of freezing, comparable to Vehicle $(P=0.97)$ and less than FADPRE and FAD-POST $\left(P^{\prime} \mathrm{s}<0.0001\right)$. These data are shown in Figure 1. These results suggest that inhibiting the conversion of testosterone to estradiol impairs the consolidation of extinction memories, because (1) when FAD was administered prior to extinction training, it led to impaired extinction recall without altering the acquisition of extinction learning, and (2) animals administered FAD $4 \mathrm{~h}$ after extinction training exhibited no impairments in fear extinction recall, suggesting that aromatase activity may be necessary during the early phases of memory consolidation (McGaugh 2000).

Experiment 2 sought to exclude the possibility that FAD led to an impairment in extinction recall due to the formation of state-dependent memory. This phenomenon occurs when a memory is formed under a certain state and can only be recalled when again in that same state (Todd et al. 2014). Rats received a s.c. injection of FAD or vehicle $30 \mathrm{~min}$ prior to extinction training, and then received another s.c. injection of FAD or vehicle 30 min prior to extinction recall, producing four groups: VehVeh (i.e., vehicle prior to extinction training and vehicle prior to extinction recall), FAD-Veh (i.e., FAD prior to extinction training and vehicle prior to extinction recall), Veh-FAD (i.e., vehicle prior to extinction training and FAD prior to extinction recall), and FAD-FAD (i.e., FAD prior to extinction training and FAD prior to extinction recall). If FAD causes state-dependent memory, then group FAD-FAD should exhibit good extinction recall, comparable to group Veh-Veh.

No differences in freezing levels were found throughout conditioning, as to be expected (Fig. 2). A $2 \times 2$ repeated measures ANOVA revealed a significant effect of conditioning trial $\left(F_{(4,208)}=40.17, P<0.0001\right)$, and no main effects of group, nor a significant trial-by-group interaction $\left(P^{\prime} \mathrm{s}>0.32\right)$. All groups exhibited comparable extinction acquisition on Day 2 (Fig. 2), as supported by a significant effect of extinction block $\left(F_{(5,260)}=\right.$ $59.84, P<0.0001)$, with no significant main effects of drugs, nor a significant trial-by-drug interaction $\left(P^{\prime} \mathrm{s}>0.08\right)$. At extinction recall there was a main effect of drug administered prior to extinction training $\left(F_{(1,56)}=6.8 ; P=0.012\right)$ and a main effect of drug administered prior to extinction recall $\left(F_{(1,56)}=4.675, P=\right.$ $0.035)$, and no significant interaction $(P=0.21)$ (Fig. 2). Followup Tukey's HSD tests indicated that Veh-Veh exhibited significantly lower levels of freezing than both FAD-Veh $(P=0.04)$ and FAD-FAD $(P=0.01)$; the latter two groups exhibited high and comparable levels of freezing $(P=0.93)$. Veh-FAD exhibited levels of freezing that were not significantly different from those of any group (smallest $P=0.08$, indicating a trend for Veh-FAD

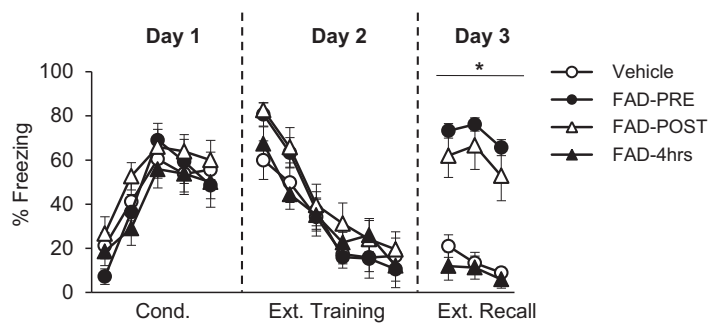

Figure 1. Mean ( \pm SEM) freezing during conditioning (Day 1$)$, extinction training (Day 2), and extinction recall (Day 3) in Experiment 1. Each extinction training block represents five CS presentations. Rats were in one of four groups: FAD-Pre $(n=12)$, FAD-Post $(n=12)$, FAD-4 h $(n=10)$, Veh $(n=12)$. $\left(^{*}\right)$ Significant difference between groups FAD-Pre and FAD-Post, compared to groups FAD-4 h and Veh. 


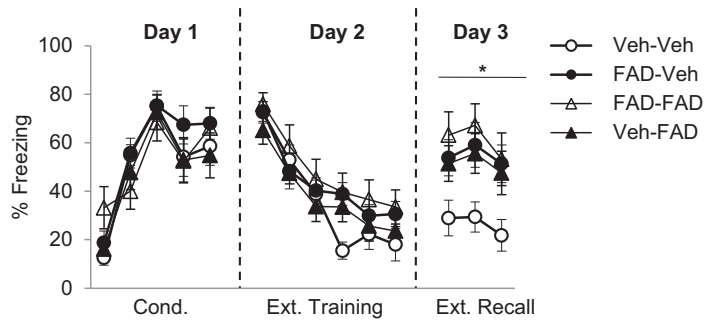

Figure 2. Mean $( \pm S E M)$ freezing during conditioning (Day 1$)$, extinction training (Day 2), and extinction recall (Day 3 ) in Experiment 2. Each extinction training block represents five CS presentations. Rats were in one of four groups: Veh-Veh $(n=15)$, FAD-Veh $(n=14)$, FAD-FAD $(n=$ $13)$, Veh-FAD $(n=14)$. (*) Significant difference between group VehVeh, compared to groups FAD-Veh and FAD-FAD. Group Veh-FAD was not significantly different from any group.

to be worse than Veh-Veh). This finding was unexpected, as it suggests that FAD may also cause a slight impairment in the expression of extinction memory. However, the important finding of Experiment 2 was that rats that received FAD prior to extinction training exhibited impaired extinction recall even when they were again administered FAD prior to test for extinction recall. This demonstrates that the impairing effect of FAD on extinction recall does not result from state-dependent memory formation, and, together with the results from Experiment 1, this suggests that FAD causes a deficit in extinction consolidation.

If the impairing effect of FAD on extinction consolidation is due to a reduction in the bioavailability of estradiol, then coadministering FAD with estradiol should attenuate the deficit. This hypothesis was tested in Experiment 3, in which two groups of rats were treated with s.c. FAD $30 \mathrm{~min}$ prior to extinction training. One group additionally received $15 \mu \mathrm{g} / \mathrm{kg}$ of body weight s.c. $17-\beta$-estradiol immediately after the FAD injection (group FAD-17ßEst); the other received an equivalent volume of vehicle (group FAD-Veh). This dose of estradiol (which produces levels of estradiol comparable to those observed during proestrus) has previously been shown to enhance fear extinction in female rats (Milad et al. 2009). A third group received two injections of vehicle (group Veh-Veh). No between-group differences in freezing levels were found throughout conditioning (Fig. 3), as to be expected. A repeated measures ANOVA revealed a significant effect of conditioning trial $\left(F_{(4,84)}=16.047, P<\right.$ $0.0001)$, and no effect of group nor a significant trial-by-group interaction $(P$ 's $>0.485)$. During extinction training on Day 2 there was a main effect of extinction block $\left(F_{(5,105)}=96.836\right.$, $P<0.0001)$, and no effect of group or block-by-group interaction $(P=0.165)$ (Fig. 3), suggesting that all groups acquired the extinction learning comparably, irrespective of drug treatment. At extinction recall on Day 3, a repeated-measures ANOVA indicated a significant effect of group $\left(F_{(2,23)}=12.585, P<0.0001\right)$ (Fig. 3). Tukey's HSD test demonstrated that FAD-Veh exhibited significantly greater freezing than FAD-17ßEst $(P=0.001)$. Veh-Veh and FAD-17ßEst exhibited low and comparable freezing levels $(P=0.99)$. These results suggest that the impairment in extinction recall caused by FAD is due to a reduction in estradiol, as estradiol supplementation at the time of FAD administration completely prevented the subsequent deficit in extinction recall.

The key findings of this study are that preventing the conversion of testosterone to estradiol by inhibiting aromatase leads to impaired extinction recall the following day. The impairment is not due to state-dependent learning from the effects of the aromatase inhibitor, because the impairment was not attenuated by readministering the aromatase inhibitor prior to extinction recall.
Rather, the impairment appears to be due to a disruption in the early consolidation phase of the extinction memory, because the aromatase inhibitor did not prevent the acquisition of extinction learning. Furthermore, administration of the inhibitor $4 \mathrm{~h}$ after extinction training occurred was ineffective in blocking extinction recall. Finally, this study also demonstrated that the deficit in extinction recall caused by inhibiting aromatase was completely rescued by coadministration of systemic estradiol.

Together, our data suggest that estradiol is necessary to fear extinction in males as it is in females. These findings are consistent with, and may account for, the pattern of results from past research demonstrating that sex differences in fear extinction are only apparent when comparing males to females who are low in estradiol (Milad et al. 2009, 2010). That is, if estradiol is necessary to fear extinction in both sexes, then males should exhibit fairly stable extinction ability as they do not undergo significant fluctuations in the production of testosterone (and its subsequent conversion to estradiol). In contrast, females should exhibit deficits in fear extinction relative to males only during periods of low estradiol, as was observed by Milad et al. $(2009,2010)$. These findings are also broadly consistent with other reports of impaired fear extinction in female mice and rodents relative to males in experiments that have not taken estrous cycle stage into account (Baran et al. 2010; Baker-Andresen et al. 2013; Fenton et al. 2014). Furthermore, one study has reported sex differences in functional activation of limbic and cortical regions during extinction recall, despite an absence of sex differences in physiological arousal (Lebron-Milad et al. 2012). Another study demonstrated that women low in sex hormone levels exhibited stronger functional activation in several limbic and cortical regions relative to males and women high in sex hormone levels during extinction learning (Merz et al. 2012). Together, these studies highlight the need to examine the hormonal basis of sex differences in emotional learning and memory.

Our findings suggest that acute inhibition of aromatase exerts rapid effects on memory consolidation in males. This is consistent with other research demonstrating rapid effects of aromatase inhibition on male behavior. For example, acute inhibition of aromatase modulates working memory in rats (Alejandre-Gomez et al. 2007), the withdrawal response from a painful stimulus in quail (Evrard and Balthazart 2004), and sexual behavior in mice (Taziaux et al. 2007). Also consistent are reports that aromatase activity itself is rapidly modulated by glutamate agonists that impact intracellular calcium concentrations (Balthazart et al. 2006), and aromatase activity is also modulated by phosphorylation processes (Charlier et al. 2011). Such findings support the notion that aromatase could rapidly modify brain activity and behavior via altering the bioavailability of estradiol.

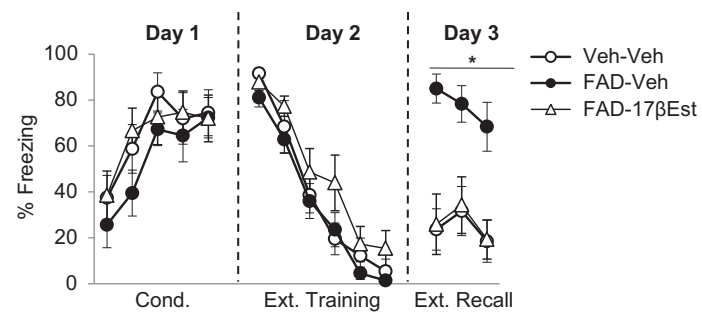

Figure 3. Mean ( \pm SEM) freezing during conditioning (Day 1$)$, extinction training (Day 2), and extinction recall (Day 3) in Experiment 3. Each extinction training block represents five CS presentations. Rats were in one of three groups: Veh-Veh $(n=8)$, FAD-Veh $(n=8)$, FAD-17ßEst $(n=$ 8). (*) Significant difference between groups Veh-Veh and FAD$17 \beta$ Est, compared to group FAD-Veh. 
The finding that disrupting the synthesis of estradiol impaired extinction consolidation, whereas a single estradiol injection reversed this effect, suggests that fear extinction in males may depend on the acute effects of estradiol synthesized de novo. The exact mechanisms by which estradiol may exert its impact on fear extinction remain to be explored. However, through interactions with its extranuclear receptors, estradiol has been demonstrated to have a myriad of nongenomic consequences that impact intracellular signal transduction, including activation of the mitogen activated protein kinase pathway, calcium influx, the protein kinase $\mathrm{C}$ and protein kinase A pathways, and accumulation of cyclic adenosine monophosphate (Sheldahl et al. 2008). Such nongenomic processes have been suggested to mediate the impact of estradiol on fear extinction in females (Lebron-Milad and Milad 2012; Graham and Milad 2013). Further studies are needed to determine whether estradiol regulates fear extinction in males and females through common pathways. This is particularly important given that sexual dimorphisms in estradiolmediated hippocampal synaptogenesis have previously been documented (Fester et al. 2012). Regardless of the mechanism, these findings highlight yet again that estradiol regulates the learned inhibition of emotional memories, and demonstrate for the first time that the role of estradiol in this regard extends to males. An increased understanding of the impact of sex hormones on fear extinction may have important implications for the treatment of anxiety disorders not just in women, but also in men.

\section{Acknowledgments}

This work was supported by the National Institute of Mental Health (NIMH) grant R01MH097880-01 and funds from the Department of Psychiatry at Massachusetts General Hospital to M.R.M. We thank members of the Milad laboratory for helpful comments on earlier versions of the manuscript.

\section{References}

Alejandre-Gomez M, Garcia-Segura LM, Gonzalez-Burgos I. 2007. Administration of an inhibitor of estrogen biosynthesis facilitates working memory acquisition in male rats. Neurosci Res 58: 272-277.

Baker-Andresen D, Flavell CR, Li X, Bredy TW. 2013. Activation of BDNF signaling prevents the return of fear in female mice. Learn Mem 20: $237-240$.

Balthazart J, Baillien M, Ball GF. 2006. Rapid control of brain aromatase activity by glutamatergic inputs. Endocrinology 147: 359-366.

Baran SE, Armstrong CE, Niren DC, Conrad CD. 2010. Prefrontal cortex lesions and sex differences in fear extinction and perseveration. Learn Mem 17: 267-278.

Chang Y-J, Yang C-H, Liang Y, Yeh C, Huang C, Hsu K. 2009. Estrogen modulates sexually dimorphic contextual fear extinction in rats through estrogen receptor $\beta$. Hippocampus 19: 1142-1150.

Charlier TD, Harada N, Balthazart J, Cornil CA. 2011. Human and quail aromatase activity is rapidly and reversibly inhibited by phosphorylating conditions. Endocrinology 152: 4199-4210.

Evrard HC, Balthazart J. 2004. Rapid regulation of pain by estrogens synthesized in spinal dorsal horn neurons. J Neurosci 24: $7225-7229$.

Fenton GE, Pollard AK, Halliday DM, Mason R, Bredy TW, Stevenson CW. 2014. Persistent prelimbic cortex activity contributes to enhanced learned fear expression in females. 21: 55-60.
Fester L, Prange-Kiel J, Zhou L, Blittersdorf BV, Böhm J, Jarry H, Schumacher M, Rune GM. 2012. Estrogen-regulated synaptogenesis in the hippocampus: sexual dimorphism in vivo but not in vitro. J Steroid Biochem Mol Biol 131: 24-29.

Garcia-Segura LM. 2008. Aromatase in the brain: not just for reproduction anymore. J Neuroendocrinol 20: 705-712.

Gillies GE, McArthur S. 2010. Estrogen actions in the brain and the basis for differential action in men and women: a case for sex-specific medicines. Pharmacol Rev 62: 155-198.

Glover EM, Jovanovic T, Mercer KB, Kerley K, Bradley B, Ressler KJ, Norrholm SD. 2012. Estrogen levels are associated with extinction deficits in women with posttraumatic stress disorder. Biol Psychiatry 72: 19-24.

Graham BM, Milad MR. 2011. The study of fear extinction: implications for anxiety disorders. Am J Psychiatry 168: 1255-1265.

Graham BM, Milad MR. 2013. Blockade of estrogen by hormonal contraceptives impairs fear extinction in female rats and women. Biol Psychiatry 73: 371-378.

Lebron-Milad K, Milad MR. 2012. Sex differences, gonadal hormones and the fear extinction network: implications for anxiety disorders. Biol Mood Anxiety Disord 2: 3.

Lebron-Milad K, Abbs B, Milad MR, Linnman C, Rougemount-Bücking A, Zeidan MA, Holt DJ, Goldstein JM. 2012. Sex differences in the neurobiology of fear conditioning and extinction: a preliminary fMRI study of shared sex differences with stress-arousal circuitry. Biol Mood Anxiety Disord 2: 7.

McGaugh JL. 2000. Memory- a century of consolidation. Science 287: $248-251$.

Merz CJ, Tabbert K, Schweckendiek J, Klucken T, Vaitl D, Stark R, Wolf OT. 2012. Neuronal correlates of extinction learning are modulated by sex hormones. Soc Cogn Affect Neurosci 7: 819-830.

Milad MR, Quirk GJ. 2012. Fear extinction as a model for translational neuroscience: ten years of progress. Annu Rev Psychol 63: 129-151.

Milad MR, Igoe SA, Lebron-Milad K, Novales JE. 2009. Estrous cycle phase and gonadal hormones influence conditioned fear extinction. Neuroscience 164: 887-895.

Milad MR, Zeidan MA, Contero A, Pitman RK, Klibanski A, Rauch SL, Goldstein JM. 2010. The influence of gonadal hormones on conditioned fear extinction in healthy humans. Neuroscience 168: $652-658$.

Parsons RG, Ressler KJ. 2013. Implications of memory modulation for post-traumatic stress and fear disorders. Nat Neurosci 16: $146-153$.

Rey CD, Lipps J, Shansky RM. 2013. Dopamine d1 receptor activation rescues extinction impairments in low-estrogen female rats and induces cortical layer-specific activation changes in prefrontalamygdala circuits. Neuropsychopharmacology 39: 1282-1289.

Sheldahl LC, Shapiro RA, Bryant DN, Koerner IP, Dorsa DM. 2008. Estrogen induces rapid translocation of estrogen receptor $\beta$, but not estrogen receptor $\alpha$, to the neuronal plasma membrane. Neuroscience 153: $751-761$.

Taziaux M, Keller M, Bakker J, Balthazart J. 2007. Sexual behavior activity tracks rapid changes in brain estrogen concentrations. J Neurosci 27: 6563-6372.

Todd TP, Vurbric D, Bouton ME. 2014. Behavioral and neurobiological mechanisms of extinction in Pavlovian and instrumental learning. Neurobiol Learn Mem 108: 52-64.

Wright CL, Schwarz JS, Dean SL, McCarthy MM. 2010. Cellular mechanisms of estradiol-mediated sexual differentiation of the brain. Trends Endocrinol Metab 21: 553-561.

Zeidan MA, Igoe SA, Linnman C, Vitalo A, Levine JB, Klibanski A, Goldstein JM, Milad MR. 2011. Estradiol modulates medial prefrontal cortex and amygdala activity during fear extinction in women and female rats. Biol Psychiatry 70: 920-927.

Received February 24, 2014; accepted in revised form May 6, 2014. 


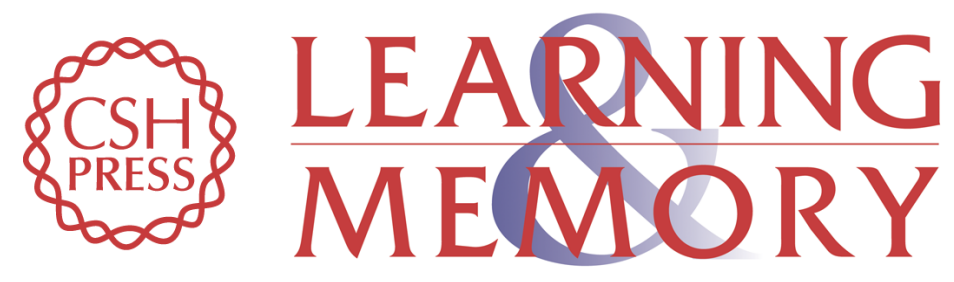

\section{Inhibition of estradiol synthesis impairs fear extinction in male rats}

Bronwyn M. Graham and Mohammed R. Milad

Learn. Mem. 2014, 21:

Access the most recent version at doi:10.1101//m.034926.114

References This article cites 27 articles, 6 of which can be accessed free at: http://learnmem.cshlp.org/content/21/7/347.full.html\#ref-list-1

Creative This article is distributed exclusively by Cold Spring Harbor Laboratory Press for the Commons first 12 months after the full-issue publication date (see

License http://learnmem.cshlp.org/site/misc/terms.xhtml). After 12 months, it is available under a Creative Commons License (Attribution-NonCommercial 4.0 International), as described at http://creativecommons.org/licenses/by-nc/4.0/.

Email Alerting Receive free email alerts when new articles cite this article - sign up in the box at the Service top right corner of the article or click here. 